\title{
Immunodeficiency in Vici Syndrome: A Heterogeneous Phenotype
}

\author{
Andrea Finocchi, ${ }^{1 *}$ Giulia Angelino, ${ }^{1}$ Nicoletta Cantarutti, ${ }^{1}$ Maurizio Corbari, ${ }^{2}$ Elsa Bevivino, ${ }^{3}$ \\ Simona Cascioli, ${ }^{4}$ Francesco Randisi, ${ }^{5}$ Enrico Bertini, ${ }^{6}$ and Carlo Dionisi-Vici ${ }^{3}$
}

${ }^{1}$ Division of Immunology and Infectious Disease, University Hospital Department of Pediatrics, University of Rome "Tor Vergata" and Children's Hospital Bambino Gesù, Rome, Italy

${ }^{2}$ Division of Anesthesiology and Intensive Care, Emergency Department, Children's Hospital Bambino Gesù, Palidoro (Rome), Italy

${ }^{3}$ Division of Metabolism, Department of Pediatric Medicine, Children's Hospital Bambino Gesù, Rome, Italy

${ }^{4}$ Division of Cytometry and B-cell Development, Research Center, Children's Hospital Bambino Gesù, Rome, Italy

${ }^{5}$ Division of Radiology, Department of Imaging, Children's Hospital Bambino Gesù, Palidoro (Rome), Italy

${ }^{6}$ Division of Molecular Medicine for Neuromuscular Disease, Department of Neurosciences, Children's Hospital Bambino Gesù, Rome, Italy

Received 20 January 2011; Accepted 29 June 2011

Vici syndrome is a rare congenital multisystem disorder characterized by agenesis of the corpus callosum, hypotonia, developmental delay, hypopigmentation, cataract, cardiomyopathy, and immunological abnormalities. Recurrent infections, mainly affecting the respiratory tract, have been reported in the majority of cases, representing an important risk factor for morbidity and mortality. The immunological phenotype of patients is extremely variable, ranging from a combined immunodeficiency to nearly normal immunity. We report on a new patient with Vici syndrome, in whom we have extensively investigated immunological features. Despite a mild impairment of the cellular compartment, a defect of humoral immunity was found, requiring treatment with intravenous immunoglobulin. A wider knowledge of immune system abnormalities of Vici syndrome will help to plan strategies for treatment and prevention of infections, such as immunoglobulin replacement and antimicrobial prophylaxis, resulting in improved survival rates.

(C) 2011 Wiley Periodicals, Inc.

Key words: Vici syndrome; agenesis of the corpus callosum; recurrent infections; immunodeficiency; hypogammaglobulinemia; intravenous immunoglobulin (IVIG)

\section{INTRODUCTION}

Dionisi Vici et al. [1988] first described two siblings with agenesis of the corpus callosum, cutaneous hypopigmentation, bilateral cataract, cleft lip and palate, and combined immunodeficiency. Thereafter other 10 similar cases have been reported, contributing to describe clinical and laboratory features of Vici syndrome [OMIM 242840] [Del Campo et al., 1999; Chiyonobu et al., 2002; Miyata et al., 2007; Al-Owain et al., 2010; McClelland et al., 2010]. All patients presented with recurrent infections and showed variable immunological abnormalities, however, their immune system has not been investigated in detail.
How to Cite this Article:

Finocchi A, Angelino G, Cantarutti N, Corbari M, Bevivino E, Cascioli S, Randisi F, Bertini E, Dionisi-Vici C. 2011. Immunodeficiency in Vici syndrome: A heterogeneous phenotype.

Am J Med Genet Part A.

We report on an infant with findings consistent with a clinical diagnosis of Vici syndrome including agenesis of the corpus callosum, profound hypotonia and development delay, cataract, progressive heart failure, relative hypopigmentation of the hair, recurrent infections, and immunodeficiency. A brief review of the literature on Vici syndrome immunological abnormalities is also presented.

\section{CLINICAL REPORT}

This boy is the first child of a nonconsanguineous couple of Italian origin. He was born at term, after an uneventful pregnancy, by normal vaginal delivery with meconium-stained amniotic fluid. His birth weight was $3.750 \mathrm{~kg}$, height was $56 \mathrm{~cm}$, and $\mathrm{OFC}$ was $35.5 \mathrm{~cm}$. On the second day of life he developed respiratory distress and sepsis of unknown origin. Transfontanellar ultrasonography

\section{${ }^{\star}$ Correspondence to:}

Andrea Finocchi, Unit of Immunology and Infectious Disease, University Hospital Department of Pediatrics, Children Hospital Bambino Gesù, Rome and University of Rome "Tor Vergata", Piazza Sant'Onofrio, 4-00165 Rome, Italy. E-mail: andrea.finocchi@uniroma2.it

Published online in Wiley Online Library

(wileyonlinelibrary.com).

DOI 10.1002/ajmg.a.34244 
(US) suggested an agenesis of the corpus callosum, confirmed by brain magnetic resonance imaging (MRI). He had profound cervicoaxial hypotonia, bilateral horizontal nystagmus, sucking difficulties with frequent regurgitation, relative hypopigmentation of the hair (slightly lighter than his parents).

At the age of 2 months, he was admitted because of feeding difficulties and failure to thrive. Swallowing incoordination was documented and necessitated tube feeding. Pharyngomalacia was detected by bronchoscopy. Electroencephalogram (EEG) demonstrated asynchronous neuronal activity with multifocal spike abnormalities. Polysomnography showed mild obstructive sleep apnea/hypopnea syndrome, associated to mild desaturation. There were no abnormal findings in abdominal US and echocardiogram. Immunological studies revealed normal values for patient's age: WBC 9,990 $\mathrm{ml}^{-1}$ (n.v. 7,200-18,000), total lymphocyte count $4,210 \mathrm{ml}^{-1}$ (n.v. 3,400-7,600), and immunoglobulin levels IgA 22 mg/dl (n.v. 8-74), IgG 626 mg/dl (n.v. 231-947), IgM $59 \mathrm{mg} / \mathrm{dl}$ (n.v. 26-2,010). Because of the finding of hypertransaminasemia (AST $155 \mathrm{UI} / \mathrm{L}$, ALT $122 \mathrm{UI} / \mathrm{L}$ ) and increased level of creatine phosphokinase (CPK $522 \mathrm{UI} / \mathrm{L}$ ) a muscle biopsy was performed, revealing many hypoplastic fibers (mostly type 1) and around the $10 \%$ of fibers with internal nuclei. With Gomori trichrome staining, many fibers showed increased fucsinophilic material in addition to increased oxidative stain. Ultrastructural examination revealed abnormally shaped and enlarged mitochondria with osmiophilic inclusions.

The boy needed other two admissions at the age of 3 and 5 months, respectively, for bronchiolitis and aspiration pneumonia, after which he required a gastrostomy tube. Bilateral cataract was detected at 7 months and corrected surgically at 1 year. Visual evoked potentials (VEPs) 6 months after surgery showed a normal response. Brainstem auditory evoked potentials (BAEPs) documented a left sensorineural hearing loss. Since the age of 10 months the child has suffered from generalized tonic seizures, resistant to common anticonvulsants therapy. Cardiac follow-up revealed progressive systolic dysfunction with mild left ventricular dilatation and mild mitral regurgitation.

Immunological work-up revealed a combined immunodeficiency (Table I). A progressive reduction of absolute lymphocyte count was observed during follow-up; distribution of naive and memory $T$ cells revealed a reduction of naïve $T$ subsets $(C D 4+C D 45+R A+$; $\mathrm{CD} 8+\mathrm{CD} 45+\mathrm{RA}+)$. In vitro stimulation of $\mathrm{PBMC}$ with mitogens and antigen as well as the analysis of peripheral blood TCR repertoire did not reveal any abnormal finding. Serum immunoglobulin and IgG subclasses were normal for age, but he showed unprotective antibody responses to tetanus and pneumococcal, with which he had been immunized. Low titers of isohemoagglutinins were detected. He had normal absolute count of B cells (CD19+), but memory B cells (CD19+CD27+) were almost absent and peripheral B lymphocytes did not respond to stimulation with $\mathrm{CpG}$.

At the age of 25 months, the boy was admitted for respiratory distress and aspiration pneumonia, for which he needed tracheal intubation for 4 weeks and received antibiotic and supportive therapy. Brain MRI showed agenesis of corpus callosum in addition to cerebellar hypoplasia, pontine hypoplasia and mildly increased subarachnoid spaces (Fig. 1). Because of the decrease of IgG values (down to $336 \mathrm{mg} / \mathrm{dl}$ ) intravenous immunoglobulin (IVIG) were administered twice at $400 \mathrm{mg} / \mathrm{kg} /$ dose, with a little increase of IgG level (up to $555 \mathrm{mg} / \mathrm{dl}$ ). Considering his severe neurological dysfunction with swallowing incoordination, he underwent a salivary ducts ligation (Fig. 2).

After discharge, he continued treatment with IVIG every 4 weeks and his follow-up has been completely uneventful for the next 4 months, with a marked improvement of general clinical conditions and no infective episodes. An improvement of his neurological symptoms was also observed; he shows a better interaction with the external environment and seizures are now well controlled with anticonvulsants.

The patient is still alive and growing well (around the 50th centile for height and weight) at the age of 2 years and 10 months.

\section{DISCUSSION}

Our patient is the 13th case with Vici syndrome [OMIM 242840], a rare congenital multisystem disorder characterized by agenesis of the corpus callosum, hypotonia, developmental delay, cataracts, cardiomyopathy, hypopigmentation, recurrent infections, and immunological abnormalities. It is likely to be inherited as an autosomal recessive trait [Del Campo et al., 1999; Chiyonobu et al., 2002; Miyata et al., 2007], although the genetic defect is still unknown. Phenotypical presentation is extremely variable and diagnosis is currently based on a suggestive combination of clinical features.

A summary of clinical aspects of reported patients with Vici syndrome is shown in Table II. Agenesis of the corpus callosum, associated with hypotonia and severe psychomotor and growth retardation, has been reported in all children. In eight of them, including our patient, other CNS abnormalities were found, such as cerebellar and cortical alterations [Dionisi Vici et al., 1988; Del Campo et al., 1999; Miyata et al., 2007; Al-Owain et al., 2010]. All children had variable hypopigmentation, ranging from complete albinism to an isolated mild depigmentation of retina [Chiyonobu et al., 2002], sometimes associated with facial dysmorphism. Our patient does not show dysmorphic facial features and his hair is slightly lighter than his parents. Such variability may suggest either variable expression of the gene to be discovered, or molecular genetic heterogeneity. Other common findings in Vici syndrome are cardiomyopathy and cataracts, both present in our child, as well as seizures. Evidence of myopathy has been described in all four patients who underwent muscle biopsy, including our boy [Del Campo et al., 1999; Al-Owain et al., 2010; McClelland et al., 2010]. A sensorineural hearing loss was documented in our patient and in one previous case [McClelland et al., 2010]. As it may be an associated feature of Vici syndrome, it should be appropriately investigated; indeed it may be overlooked because of the neurological impairment.

All reported Vici patients had recurrent infections, mainly affecting the respiratory tract, in infancy. Aspiration pneumonia due to hypotonia and swallowing incoordination occurred in four patients (three episodes in our boy) [Del Campo et al., 1999; Miyata et al., 2007]. Mucocutaneous candidiasis was notably frequent (six patients) [Dionisi Vici et al., 1988; Del Campo et al., 1999; Chiyonobu et al., 2002; Al-Owain et al., 2010], as well as sepsis (four patients, included our child) [Dionisi Vici et al., 1988; Chiyonobu 
TABLE I. Immunological Profile of Our Patient With Vici Syndrome

\begin{tabular}{|c|c|c|c|c|c|}
\hline \multirow[b]{2}{*}{ Immunological data } & \multicolumn{3}{|c|}{ Results } & \multicolumn{2}{|c|}{ Age-matched control } \\
\hline & 18 months & 23 months & 25 months & $1-2$ years & $2-3$ years \\
\hline \multicolumn{6}{|c|}{ Serum immunoglobulin levels $(\mathrm{mg} / \mathrm{dl})$} \\
\hline $\lg A$ & 38 & 36 & 42 & $17-178$ & $27-173$ \\
\hline $\lg M$ & 53 & 80 & 105 & $48-337$ & $62-257$ \\
\hline $\lg G$ & 847 & 433 & 336 & $264-1,509$ & $462-1,710$ \\
\hline $\lg G 1$ & 445 & ND & ND & 268-890 & \\
\hline $\operatorname{lgG2}$ & 38.8 & ND & ND & $31-185$ & \\
\hline $\operatorname{lgg} 3$ & 15.4 & ND & ND & $7-58$ & \\
\hline $\operatorname{lgG} 4$ & 2.41 & ND & ND & & \\
\hline \multicolumn{6}{|l|}{ Antibody response } \\
\hline Tetanus & 0.01 & ND & ND & \multicolumn{2}{|c|}{$>0.1 \mathrm{IU} / \mathrm{ml}$} \\
\hline PCP & 21 & 10 & ND & \multicolumn{2}{|c|}{$>35 \mathrm{mg} / \mathrm{l}$} \\
\hline $\mathrm{HiB}$ & 2.1 & ND & ND & \multicolumn{2}{|c|}{$>1 \mathrm{mg} / \mathrm{l}$} \\
\hline \multicolumn{6}{|l|}{ Isohemoagglutinins } \\
\hline Anti-A antibodies & $1: 4$ & ND & ND & \multicolumn{2}{|c|}{$\geq 1: 8$} \\
\hline Anti-B antibodies & Absent & ND & ND & \multicolumn{2}{|c|}{$\geq 1: 8$} \\
\hline Lymphocyte count $/ \mathrm{mm}^{3}$ & 2,610 & 1,270 & 1,600 & $3,600-8,900$ & $2,300-5,400$ \\
\hline \multicolumn{6}{|l|}{ Immunophenotype } \\
\hline $\mathrm{CD} 3+$ & $55.5 \%(1,448)$ & $63.6 \%$ [807] & $67.1 \%(1,073)$ & $53-75 \%(2,100-6,020)$ & $60-76 \%(1,400-3,700)$ \\
\hline $\operatorname{CD} 4+$ & $40 \%(1,044)$ & $43.2 \%[548]$ & $42.7 \%(683)$ & $32-51 \%(1,300-3,400)$ & $31-47 \%(700-2,200)$ \\
\hline CD4+ CD45 RA & $62 \%(652)$ & $76 \%(424)$ & ND & $63-91 \%(1,000-2,900)$ & \\
\hline $\mathrm{CD} 4+\mathrm{CD} 45 \mathrm{RO}$ & $35 \%[365]$ & $23 \%(128)$ & ND & $7-20 \%(210-850)$ & \\
\hline $\mathrm{CD} 8+$ & $14 \%[365]$ & $18.2 \%[231]$ & $22.2 \%(335)$ & $14-30 \%(620-2,000)$ & $18-35 \%(490-1,300)$ \\
\hline $\mathrm{CD} 8+\mathrm{CD} 45 \mathrm{RA}$ & $71 \%$ [261] & $87 \%$ (203) & ND & $71-98 \%(490-1,700)$ & \\
\hline $\mathrm{CD} 8+\mathrm{CD} 45 \mathrm{RO}$ & $21 \%(78)$ & $4 \%[27]$ & ND & $2-12 \%(60-570)$ & \\
\hline CD19+ & $32 \%[835]$ & $23 \%[292]$ & $14 \%[224]$ & $16-35 \%(720-2,600)$ & $13-27 \%(390-1,400)$ \\
\hline B phenotype & ND & $\begin{array}{l}\text { B cells all mature-naïve } \\
\text { and transitional [ } 49 \% \text { ]. } \\
\text { Almost absent } \\
\text { memory B cells. } \\
\text { No response to CpG }\end{array}$ & ND & & \\
\hline CD16/56+ & $8.4 \%(219)$ & $9.8 \%(124)$ & $19.3 \%$ [308] & $3-15 \%(180-920)$ & $4-17 \%(130-720)$ \\
\hline Response to mitogens (CPM) & & & & Health & control \\
\hline Unstipulated & ND & ND & 1,758 & & 01 \\
\hline PHA & ND & ND & 60,185 & 86 & 116 \\
\hline PWM & ND & ND & 36,853 & 39 & 13 \\
\hline OKT3 & ND & ND & 38,971 & 38 & 386 \\
\hline \multicolumn{6}{|l|}{ Response to antigens } \\
\hline Candida & ND & ND & 4,738 & & \\
\hline $\mathrm{CD} 3+\mathrm{CD} 4+/ \mathrm{CD} 3+\mathrm{CD} 8+$ & ND & Polyclonal & ND & Poly & Ional \\
\hline
\end{tabular}

et al., 2002; Al-Owain et al., 2010]. Less common infections were UTI, gastroenteritis, bacterial conjunctivitis, and perineal abscess. Immunological studies were performed in all patients but one (Table III). In four of them results were normal for age. In the other eight children variable alterations were found: lymphopenia associated with different combinations of specific $\mathrm{T}$ cell subsets defect was the most frequent immunological abnormality identified (six out of eight patients); one boy presented also leucopenia and neutropenia; hypogammaglobulinemia has been reported in the two firstly described patients, in addition to the lack of skin responses to several recall antigens. In most children the early death (Table III) did not allow a complete immunological evaluation. On the basis of these data it is clear that the immune system of patients with Vici syndrome is often compromised, although the spectrum of the immune defect is very broad, ranging from a combined immunodeficiency to a nearly normal immunity. In our child (almost 3 years follow-up) we could observe a progressive lymphopenia with a normal distribution of lymphocytes subsets [Shearer et al., 2003]. Despite these results proliferation response to antigens and mitogens a TCR repertoire were normal, excluding a 

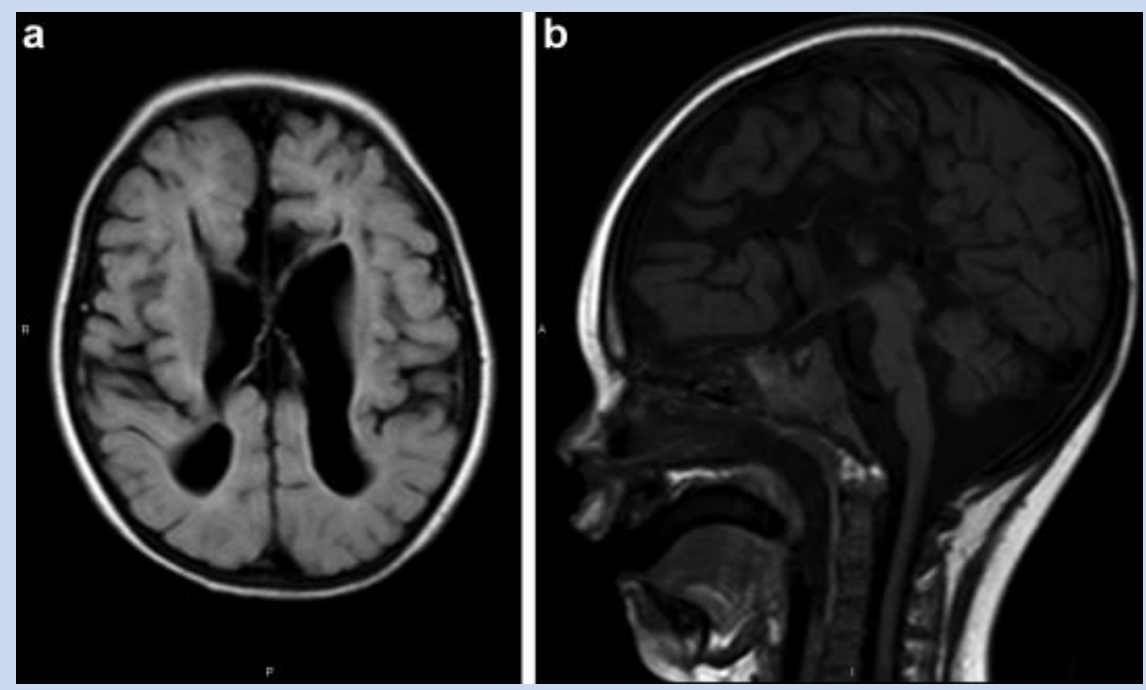

FIG. 1. MRI of the patient performed at age 2 years. Axial FLAIR section showing complete agenesis of corpus callosum, enlarged ventricles, and moderately increased subarachnoid spaces [a]. Sagittal T1 weighted section showing agenesis of the corpus callosum and hypoplasia of the cerebellum and of the pons [b].

major defect of $\mathrm{T}$ cell compartment. On the other hand, a reduction of absolute IgG values and isohemoagglutinins was detected as well as a lack of specific antibody response against tetanus and pneumococcal and a defect of memory B cells [Huck et al., 2009], revealing an impairment of humoral immune compartment. These alterations could be evocative of a common variable immunodefi-

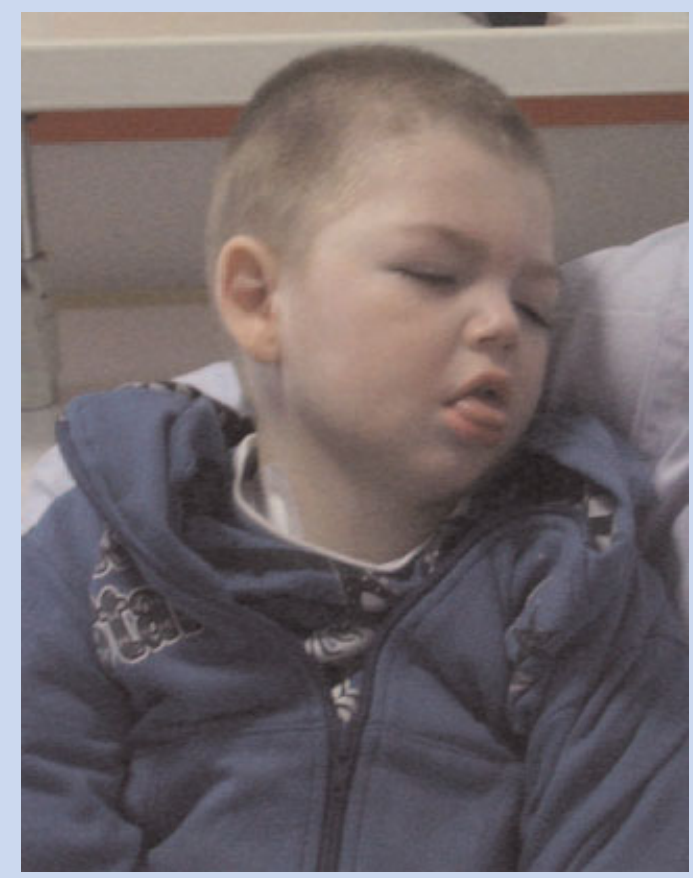

FIG. 2. The patient at age 2 years and 6 months. [Color figure can be seen in the online version of this article, available at http:// onlinelibrary.wiley.com/journal/10.1002/[ISSN]1552-4833] ciency (CVID), although this diagnosis can not be definitively confirmed because of the young age of the patient and the short follow-up [Chapel and Cunningham-Rundles, 2009].

This brief analysis confirms the presence of a heterogeneous immunological phenotype in Vici syndrome. Therefore each Vici patient could present with a different pattern and degree of immunodeficiency, as it has been reported in other complex syndromes with immunodeficiency, such as Di George syndrome

\section{TABLE II. Clinical Features of 13 Reported Patients With Vici Syndrome}

\section{Clinical features}

Agenesis of the corpus callosum

Other CSN anomalies

Hypotonia

Developmental delay

Seizures

Hypopigmentation

Facial dysmorphism

Frequency $13 / 13^{a}$

$8 / 12^{a}$

$13 / 13^{a}$

$13 / 13^{a}$

$8 / 13^{a}$

$12 / 12$

$10 / 13$

Growth retardation

$13 / 13^{a}$

Cataracts

$9 / 13^{a}$

Visual disturbance

$9 / 11$

Cardiomegaly/cardiomyopathy

Recurrent infections

Immunological abnormalities

Elevated muscle enzymes

Abnormal muscle biopsy

$12 / 13^{a}$

$13 / 13^{a}$

$8 / 12^{a}$

$7 / 7^{\mathrm{a}}$

$4 / 4^{\mathrm{a}}$

Renal tubular acidosis

$3 / 5$

Lung hypoplasia

$1 / 13$

Hearing loss

$2 / 13^{a}$

ancluding our patient. 


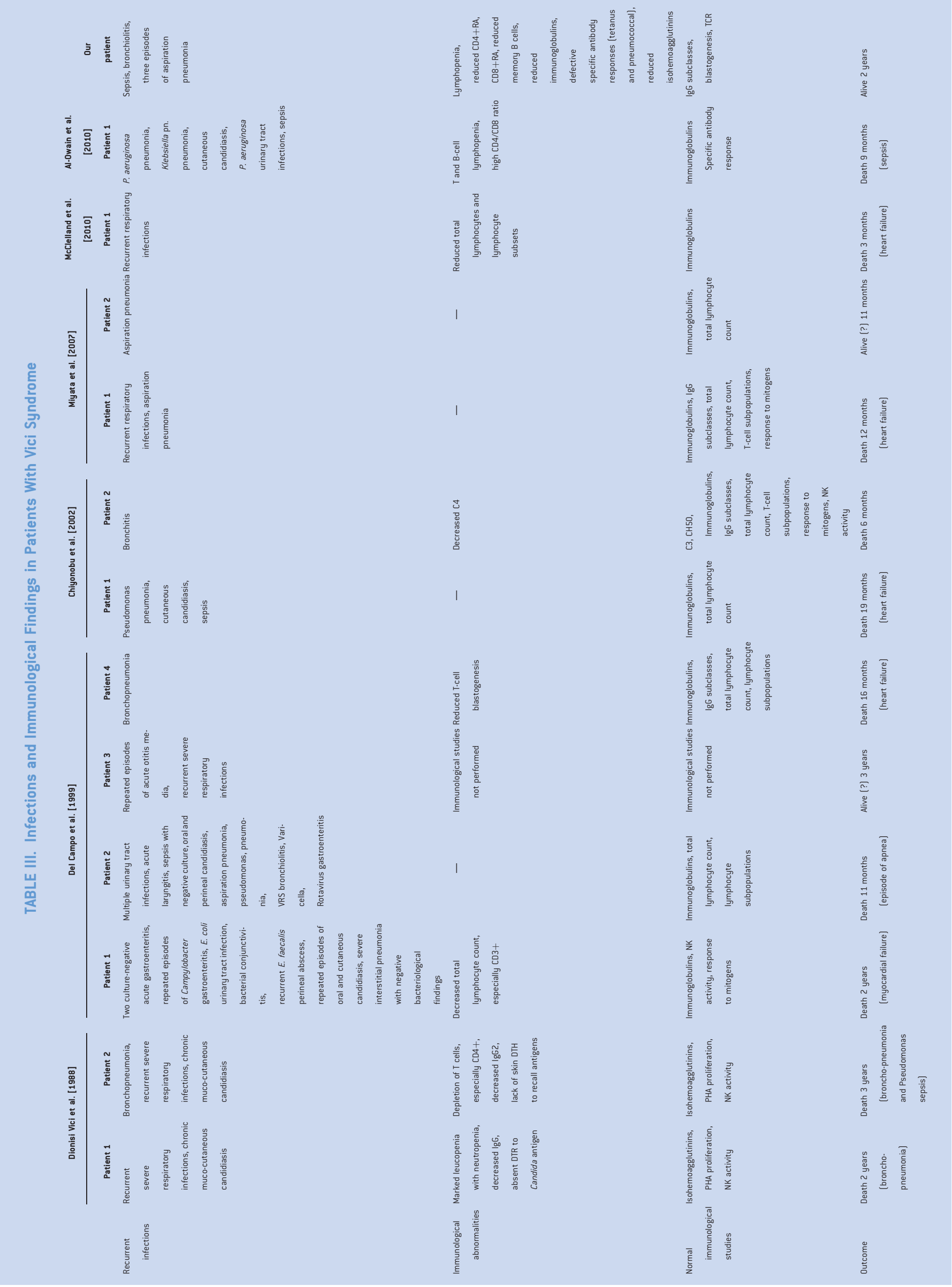


[McLean-Tooke et al., 2007] and ataxia-telangiectasia [NowakWegrzyn et al., 2004].

Further studies on a larger group of Vici children are needed to better understand their immunological defect as well as the role of immunodeficiency in recurrent infections; in these children other factors can contribute to the risk of infections, such as anatomical defects, cardiac disease, profound hypotonia, poor nutrition, and invasive medical procedures.

In conclusion, we recommend a complete evaluation of immune system of Vici patients including the humoral compartment by determining serum immunoglobulins, IgG subclasses, isohemoagglutinins, and the evaluation of specific antibody response against vaccine antigens, as well as the characterization of peripheral $\mathrm{T}$ and $\mathrm{B}$ cells by flow cytometry and the lymphocyte proliferative response to mitogens and antigens.

A wider knowledge of Vici syndrome immunological features will help to plan strategies for treatment and prevention, such as immunoglobulin replacement and antimicrobial prophylaxis. Our patient showed a significant improvement of general clinical conditions and he has not had any further infection since IVIG treatment was started. Although the long-term efficacy of IVIG should be assessed in a larger time interval, considering the presence of other risk factors for infections we suggest treating hypogammaglobulinemic Vici patients with immunoglobulin replacement therapy. This could result in a significant decrease in the number and severity of infections with improved survival rates.

\section{ACKNOWLEDGMENTS}

We thank the parents of our patient for their participation and support. We are grateful to Dr. M. L. Romiti who performed the $\mathrm{T}$-cell repertoire analysis and in vitro proliferation assay.

\section{REFERENCES}

Al-Owain M, Al-Hashem A, Al-Muhaizea M, Humaidan H, Al-Hindi H, Al-Homoud I, Al-Mogarri I. 2010. Vici syndrome associated with unilateral lung hypoplasia and myopathy. Am J Med Genet Part A 152:1849-1853.
Chapel H, Cunningham-Rundles C. 2009. Update in understanding common variable immunodeficiency disorders (CVIDs) and the management of patients with these conditions. Br J Haematol 145:709-727.

Chiyonobu T, Yoshihara T, Fukushima Y, Yamamoto Y, Tsunamoto K, Nishimura Y, Ishida H, Toda T, Kasubuchi Y. 2002. Sister and brother with Vici syndrome: Agenesis of the corpus callosum, albinism, and recurrent infections. Am J Med Genet 109:61-66.

Del Campo M, Hall BD, Aeby A, Nassogne M-C, Verloes A, Roche C, Gonzalez C, Sanchez H, Garcia-Alix A, Cabanas F, Escudero RM, Hernandez R, Quero J. 1999. Albinism and agenesis of the corpus callosum with profound developmental delay: Vici syndrome, evidence for autosomal recessive inheritance. Am J Med Genet 85:479-485.

Dionisi Vici C, Sabetta G, Gambarara M, Vigevano F, Bertini E, Boldrini R, Parisi SG, Quinti I, Aiuti F, Fiorilli M. 1988. Agenesis of the corpus callosum, combined immunodeficiency, bilateral cataract, and hypopigmentation in two brothers. Am J Med Genet 29:1-8.

Huck K, Feyen O, Ghosh S, Beltz K, Bellert S, Niehues T. 2009. Memory B-cells in healthy and antibody-deficient children. Clin Immunol 131: 50-59.

McClelland V, Cullup T, Bodi I, Ruddy D, Buj-Bello A, Biancalana V, Boehm J, Bitoun M, Miller O, Jan W, Menson E, Amaya L, Trounce J, Laporte J, Mohammed S, Sewry C, Raiman J, Jungbluth H. 2010. Vici syndrome associated with sensorineural hearing loss and evidence of neuromuscular involvement on muscle biopsy. Am J Med Genet Part A 152:741-747.

McLean-Tooke A, Spickett GP, Gennery AR. 2007. Immunodeficiency and autoimmunity in 22q11.2 deletion syndrome. Scand J Immunol $66: 1-7$.

Miyata R, Hayashi M, Sato H, Sugawara Y, Yui T, Araki S, Hasegawa T, Doi S, Kohyama J. 2007. Sibling cases of Vici syndrome: Sleep abnormalities and complications of renal tubular acidosis. Am J Med Genet Part A 143:189-194.

Nowak-Wegrzyn A, Crawford TO, Winkelstein JA, Carson KA, Lederman HM. 2004. Immunodeficiency and infections in ataxia-telangiectasia. J Pediatr 144:505-511.

Shearer WT, Rosenblatt HM, Gelman RS, Oyomopito R, Plaeger S, Stiehm ER, Wara DW, Douglas SD, Luzuriaga K, McFarland EJ, Yogev R, Rathore MH, Levy W, Graham BL. Spector SA, Pediatric AIDS Clinical Trials Group. 2003. Lymphocyte subsets in healthy children from birth through 18 years of age: The Pediatric AIDS Clinical Trials Group P1009 study. J Allergy Clin Immunol 112:973-980. 